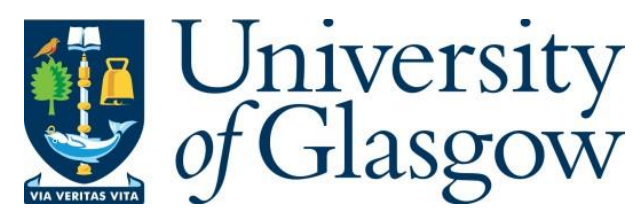

Barker, T. (2017) Experiments with time: the technical image in media art and the digital humanities. Visual Communication, 16(4), pp. 375-394.

There may be differences between this version and the published version. You are advised to consult the publisher's version if you wish to cite from it.

http://eprints.gla.ac.uk/100262/

Deposited on: 2 October 2017

Enlighten - Research publications by members of the University of Glasgow http://eprints.gla.ac.uk 


\section{Experiments with time: The technical image in video art, new media and the digital humanities}

\section{Tim Barker}

\section{The University of G lasgow}

The experimental is pervasive throughout culture, and, for many of us, life is increasingly an experimental process, in which to a lesser or greater extent we need to reinvent our bodies, ourselves and our community - culture is the laboratory in which these experiments take place and our media are some of the principle tools we use.

Charlie Gere 'Research as A rt', p. 3

In M ark Hansen and Ben Rubin's M oveable Type (2007) 560 small vacuumfluorescent tubes are assembled in two linear displays in the lobby of the New $\mathrm{Y}$ ork Times. The work gathers live data feeds from the upstairs offices, al ong with visitor comments taken from the Times' website and historical data drawn from their 150 year archive and uses natural language processing routines to combine these into linguistic patterns. Hansen and Rubin's installation, designed to provide a portrait of the history of the company and its daily news gathering and generating routines, reassembles and dramatises archival and 'real-time' data based on a set of technical protocols. It is a way of making public the socially composed memory of an institution, letting a computer program mediate the archive and re-present it in meaningful and often poetic combinations. 
M oveable Type is based on Hansen and Rubin's previous work Listening Post, an experimental investigation into the 'chatter' of early 2000s internet culture. Listening Post (2002) (fig. 1), now on permanent exhibition at the London Science Centre, uses 110 similar small vacuum-fluorescent tubes to display text, scraped in real time from open access social media sites and vocal ised by a computer synthesised voice. A gain, the use of natural language processing routines allows Listening P ost to parse this 'real-time' data and trigger it based on linguistic patterns (H ansen and Rubin, 2002). The first movement invokes sentences that begin with the words 'I am...' , giving audiences the opportunity to listen to pieces of online communication, which are removed from their usual context and put in new relations with other entries. Other movements truncate the text feeds, reducing them to single words or short phrases that overlap one another and seem to come too quickly to be understood. In both installations words and sentences cascade over the screens in organised and complex patterns and in both there is a layering and overlapping of text and voice. Institution, archive, technology and individual are heard at once. The works are, as L ucy Bullivant (2005: 91) points out, a visual and sonic response to the content, magnitude and immediacy of virtual communication. They are a way of making data aesthetic in that they re-animate the archive by introducing a layer of data management software, combined with a scripting of sounds and images designed to make the unfolding relationships between data affectively felt in the installation space.

B oth works offer a way to address questions of social memory, archives, historical time, data management and online communication in an aesthetic experiment. By creatively organising an archive of social media data, they experimentally and experientially grapple with questions to do with the material technologies of memory 
and the role of data storage and management in re-imagining concepts of linear time. Through their content, they provide a way to approach time-based concepts via images. But they also offer a way to think about time through their technical architecture. Using these works as a starting point and inspired by a tradition of the materially-oriented philosophy of media, in this paper I am interested in exploring how the technically produced images of video art, new media and the digital humanities produce new ways to think about the production of time in contemporary media culture.

The works that I explore here provide the opportunity to work concepts of time through both percepts and affects, as what is seen and what is felt by a viewer. But they also provide the opportunity to generate new experiences of and ideas about time through levels of technology. In the wake of media philosophers such as W olfgang Ernst and Vilém Flusser, in this paper I want to explore the relationship between the image, its interaction with a viewer and the technological processes, at the level of hardware and programming, that both produced it and are vicariously experienced through it. M y hope is that, as well as contributing to the media philosophy of the technical image, this will add to discussion that formalise image-making practice as research (Scrivener, 2002 and 2004; Candy, 2006; Nelson, 2013) by proposing a type of practice in the arts and humanities that could be described as a technically mediated mode of experimental inquiry.

This paper is part of a larger research project on experimental methods in culture and in it I begin to identify a new way to conceptualise the term 'experiment' in the arts 
and humanities. Generally speaking, the experiment is a mode of inquiry that manipulates by technical means the condition of a system under observation in order to further explore the conditions of this system. In other words, an experiment creates new phenomena in order to better understand the pre-experimental world (Hacking, 1983: 228). In science, an experimental researcher usually applies an independent variable to a dependent variable and asks what are the effects of $X$ (the independent variable) on $Y$ (the dependent variable)? Through this process the experimental scientist aims to create an effect that tells us something about the condition of the dependent variable. In experimental art the artist likewise applies an independent variable to a system. They apply a piece of media technology and explore how the system changes in relation to this intervention. These of course are not experiments 'on' viewers. But rather experiments that provide viewers with the opportunity to think with and through technology and images. The experimental artist experimentally applies an apparatus that takes signal from the world and re-organizes it, intervening in the events of the world to show us something new about these events.

It is though this experimental process - a special case of signal processing - that the image and the technical processes by which it actualises provide the conditions for the testing - rather than the illustration or representation - of concepts. Experiments in the arts and humanities, much like experiments in science, amount to a process where, based on a set of technical parameters, the events of the world unfold in new settings that are designed by the artist. The processes involved in both Listening Post and M oveable Type, as indicative of the kinds of projects that I explore in what follows, constitute an experimental testing of online relationships in that they apply software 
and hardware to create scenarios that have no analogue in the pre-experimental world, but that nevertheless tell us something novel in their portrait of the online communication that takes place in this pre-experimental world. M y use of the term 'testing', like the use of the term in the Popper's (1935/2002) philosophy of the experiment, is not meant to connote an intention to prove or disprove a theory. Describing experiments as a 'testing' of concepts instead refers to the way experiments are designed to explore the strength of a theory in a given experimental setting. Experimental artists, like scientists, apply a method and an apparatus to test problems (though they of course do not al ways look for solutions); they experimentally apply technology and artistic technique and, much like experimental scientists, explore a problem by using an apparatus to create technical images of the world.

A fter framing the experiment as a cultural process involving the technical manipulation of a system, I then illustrate some earlier preconditions for contemporary experiments in the arts and humanities using examples that, it must be said, would al ready in the conventional vernacular of art history be considered as 'experimental art'. This includes Richard Serra's video piece Boomerang (1974) and M ichael Naimark's projection environment D isplacements (1984), which could be gathered together under the often used, but somewhat general term 'experimental' in order to distinguish them from mainstream artistic practice. By focussing on an exploration of the experiment of experimental art, I suggest that these works are not only experimental in that they somehow represent an 'underground' or 'alternative' set of practices but more precisely because they can be used to identify a type of creative practice that can be considered as experimental in its methods and 
approaches to creative inquiry. From this rethinking of the experiment in experimental art, I suggest that the approach of artists such as Serra, Naimark and Hansen and Rubin has been re-iterated in more recent developments in data visualisation and digital humanities scholarship, with a tradition of experiments with media pre-supposing contemporary work in the digital humanities.

If experimentalism is the general topic of this paper, my more particular interest is in the way artists have explored concepts of time through the application of media technology. Questions regarding technology and the production of temporality have become an increasing concern for cultural theorists. Databases, gaming, social media and networked communication have provided fertile ground for contemporary memory theorists (V an Dijk, 2007; Guarde-Hansen, Hoskins and R eading, 2009). Philosophers, film theorists and art historians have likewise paid a great deal of attention to the way that time has been generated by images, both digital and analogue (Deleuze, 1985/2005; Lee, 2006; Groom, 2013). Testing these cultural observations, experimental artists and humanities scholars, using a different set of methods to the cultural theorist, have up-scal ed these scenarios. They have used experimental methods and created new devices in which they explore the way that interactive databases, networked communication, film and computer simulations produce the time of contemporary media culture. A n example of this is Hansen and Rubin's work, where they build a new data management program to create scenarios that test the multi-temporality of digital culture, repurposing natural language processing software to generate a new image of the online organisation of data. Where cultural theorists work concepts through language, the experimental artist explores concepts through technical images. 
Throughout the paper my use of the term 'image' is not intended to signify, in the usual sense, a representation or illustration of an idea. But rather, following Flusser it is used to refer to an 'image that means ideas' (J ongen, 2011: 208). Flusser states that "since photography was invented, it is possible to philosophize not only in the medium of words, but also in that of photographs. The reason is that the gesture of photographing is a gesture of seeing, and so engages in what the antique thinkers called 'theoria', producing a picture that these thinkers called an 'idea'" (Flusser, 2011: 286). The condition that Flusser points to is one where the thinking processes afforded by the structural qualities of written language have been replaced by the thinking processes afforded by the structural qualities of technical images, produced first by photography and now by electronic communication. It is not the content of technical images that particularly concerns Flusser, but the gestures and organisational systems invested within the image, that make up its program. A fter Flusser, the image can be understood to provide the conditions for the emergence of concepts, allowing a 'picturing of thoughts', subject to the programmed technical apparatus that produces images.

Throughout this paper I use Flusser's concept of the technical image first developed in his philosophy of photography and designed to explain the image produced by the signal processing routines of a technological apparatus (Flusser, 1986: 329). For Flusser, technical apparatuses generate images automatically. Rather than an artist directing the image making process, these apparatuses function based on a set of programmatic signal processing routines. The artist now sets the conditions for these 
routines to play out. Like traditional images, the technical image presents artistic content. B ut, it also points back to the functioning and protocols of the technology that produced it. It's character is not a product of direct manipulation by an artist, but instead generated by technical protocols and processing routines. A nd it is in this sense that the term 'image' is designed to signify not a top-down and artistically 'intended' representation, but rather a more bottom-up process of providing a set of technico-aesthetic conditions for the playing out of experiments.

\section{Technical tests}

Hansen and Rubin's Listening Post can be understood as an experiment designed to test the patterns emergent when thousands of simultaneous online conversations are subject to computational data analysis (Hansen and Rubin, 2002). M oveable Type could likewise be seen as an experimental testing of the organizational memory of the New Y ork Times, putting its archive into new combinations and indicating how meaningful connections can be formed between contemporary and apparently out-ofdate text feeds. B oth works are a scaling up of the contemporary use of search engines to organise data: They intervene in computer culture by amplifying the everyday search-retrieve functions and the organisation of data associated with computer use. They demonstrate the cultural implications of organising the world based on mathematical principles and more specifically demonstrate in an experimental setting the types of time generated by such systems. Hansen and Rubin program the machine and design the installation, but it is the automatic function of the program, as it goes through its routines and processes the text feeds based on mathematical rules, which creatively re-images the temporality of electronic communication. Both works 
produce - in the sense that they demarcate off - images of the world, putting text feeds in new experimental relations, so that they can be (re-)thought in that they are (re-)imaged and (re-)organized by mathematical principles.

\section{INSERT FIGURE 1 HERE}

FIGURE 1

M ark Hansen and B en Rubin, Listening P ost (installation detail), 2002, London Science Centre

On the level of surface content, the audio-visual images of the installation provides an opportunity for viewers to experience vicariously (but experience nonetheless) the workings of a computational system. The audio-visual images of Hansen and Rubin's projects, as the effects of hardware and software processes, re-image networked relationships across different scales of time. Listening P ost pulls together text feeds that discuss identity, whether this be social, sexual, political, age, class or national, and M ovable Type puts organizational memory in contact with contemporary news gathering routines in order to generate a picture of the global and multi-temporal condition of networked communication, which ostensibly brings together events separated by distances of both space and time. Listening P ost and M oveable Type through their content speak to the multi-temporal condition of communication on a conceptual level. They provide the condition for viewers to experience social media in a new way. But the material technical processes that occur - here in an artw ork but that can also be seen to operate in a much wider digital culture - also generate temporality at the level of both the hardware and the software of the technological image making system. 
In both works the computer treats the text feeds as strings, an array of bits of information that are organised by mathematical rules. The printed word that once produced meaning in linear time, as it linked up with other words, phrases and sentences immediately before and after, is now made to operate in a multi-temporal structure based on relationships between data generated by al gorithms. As Shintaro M iyazaki (2012) points out, a computer's operation "is the result of an inter-play, orchestration and synthesis of abstract al gorithmic and calculable organisational concepts, with rhythmic real-world signals, which have measurable physical properties." Real world events are feed into the computer as signal, cut up, delayed and re-arranged. It is at this level that the technical architecture of artworks - the things that make them work - also provides a mode of experimenting with and experiencing time and it is this quality of the computer, which amounts to a continual archiving and making past of the rhythms of 'real time', that Hansen and R ubin experimentally demonstrate in M oveable Type and Listening Post. The installations not only produce new senses of space through the use of images and sounds, but, perhaps more interestingly, use the computer to produce new senses of temporalities.

A $n$ algorithm is developed for both Listening Post and M oveable Type that initiates a series of computational processes and which result in patterns of words being 'recognised' and triggered by the machine. These electronic processes involve various levels of delay, as signal is taken from the internet, queued, then stored in the computer's memory to be triggered as green text on one of the LED screens. It is seemingly true that the works bring archival data into contact with the present (Eleey, 
2003). But they do so by subjecting the present to multiple layers of delay. The present - the keys typed by N ew $\mathrm{Y}$ ork Times employees and social media users alike - is continually made past, continually archived, as it is always delayed in the circuits of Hansen and Rubin's computational machines. The types of time produced by these works speak to the continual entropy of the present when put in contact with digital machines, which archive and make 'real-time' past. Understood this way, through what Ernst (2013) calls 'time-critical' media, it is not that the past is made present. Instead the present is continuously made past by the computer. The present is continually delayed, given the same material existence as the past, so that it can become signal for the computer that is indistinguishable from the signal that it receives from the archived data. Hansen and Rubin's experiment, by scaling-up the computational ordering of data also scale-up the production of time in contemporary culture; at the centre of the work is the delayed and relational organisation of time in contemporary media culture. Hansen and Rubin have intervened in the system of computer culture, amplifying one of its features, in such a way that allows viewers to experience new elements of the operation of the system.

\section{Technical images}

In experimental art, the image and its technological architecture amounts to a setting up of an experiment. The camera and the projector become tools for the experiment as, much like the telescope, the microscope, and computer simulations, they become an apparatus for experiencing the world as an image. B oth art and science produce technical images of the world in equal measure, as the application of mathematical programs, developments in optics and scientific methods produce one image of the 
world and the experimental use of cameras, computer software and data visualisation in artworks produces another. Earlier I described the experimental artist as a figure that tests aesthetic and cultural problems. To add to this definition we could say that an experimental artist is a figure that, like $\mathrm{H}$ ansen and Rubin, tests these problems by providing the conditions for the emergence of technical images.

In the early modern world the experiment was described as a manipulation of naturally occurring events in order to observe the outcomes. The experiement was treated as a matter of fact. "Experimental results were just there to be described, brute facts, so to say. Observations were often mentioned in the same breath as experiments" (Harré, 2003: 21). But within this history, instruments al ways played some role: experimental observation was always active and invasive. They produced, following Davis Baird (2003), a type of 'thing-knowledge', or what Gaston B achelard has called a 'phenomeno-technique' (B achelard in Schuster and W atchirs, 1990: 8), a type of technical materialism where the phenomena of science are not discovered but made. For these thinkers knowledge is "threaded through the machinic field of science" (Pickering, 1995: 7), and always indebted to the material properties of this mechanism. "When a science comes into being [... ] an artificial technical realm comes into being in which phenomena are literally manufactured under the joint guidance of the system of mathematized concepts and the instruments and experimental hardware in which those concepts have been realized" (Schuster and W atchirs, 1990: 8). A s Hacking states,

most of the phenomena of modern physics are manufactured. The phenomena about the species - say the one that a pride of 
lions hunt by having the male roar and sit at home base while the females chase after and kill scared gazelle - are anecdotes. But the phenomena of physics - the Faraday effect, the Hall effect, the J osephson effect - are the keys that unlock the universe. People made the keys - and perhaps the locks in which they turn (Hacking, 1983: 228).

The experiment is then, for Hacking, a process of manipulating the conditions of the world under observation and producing phenomena to test out theories of this world. Furthermore, it is, as Gere (2010) using Latour (1993) points out, no longer a method of inquiry that is the sole purview of science. It takes place well outside the scientific lab, in culture, with mass media.

W olfgang Ernst has recently pointed out that al most all our mass media were once used as analytical or storage devices for experiments. "The phonograph, kinematograph, radio and electronic television were first developed for experimental research [...]. The well known television tube was developed out of a measuring device, Ferdinand Braun's electronic oscilloscope, just as Edison's phonograph was preceded by Léon Scott's Phonautograph, created to register the frequencies of the human voice for analytic purposes" (Ernst, 2013: 184). The early cinematic experiments of M uybridge, M arey and the later studies of Gheorghe M arinescu, developed recording, storage and transmission media that isolated and made it possible to analyse movements as frozen moments in time. As we use these devices we enact what Ernst calls a process of 'reverse experimentation'. The computer, the radio, the television and the cinema - what we now have come to know as synthetic 
media - can be returned to their analytical roots and applied by artists, users and audiences in, to again borrow Ernst's term, "time-critical" experiments.

M ichael Naimark, one of the pioneers of media art, creates such time-critical experiments in his work Displacements (1984/2005). He experimentally tests the time-based qualities of film by setting up situations that generate technical images and reformulate the traditional conventions of cinema. In D isplacement, the final piece from a series of works that explored what he terms 'relief projection' (N aimark, 2005: 598) - a technique where recorded footage is projected onto similar shaped objects a $16 \mathrm{~mm}$ camera on a turntable is panned around a room to record relatively everyday family activities. The actors then leave the room and N aimark coats the entire room and the objects within it in white paint, effectively turning the three dimensional room into a projection screen (Naimark, 2003: 111). He then replaces the camera on the turntable with a projector, which now follows the camera's original movements. The walls, the television, framed paintings, the sofa, the fruit bowl, bottles, plates, cups, everything, now become the white screen upon which the original footage is projected, as though a moving beam from a flashlight (Naimark, 2003: 111). The concrete whitewashed object, as an image in the present, and the projected image, as an image of the past preserved via recording techniques, are thus tensioned in this work, as the past is projected on top of the present.

A ctors move around the room, sitting on the 'real' sofa, adjusting the 'real' picture frame, moving the 'real' objects. In these moments the appearance of objects as both 'hard' ontological facts and 'softer' cinematic images is based on both their existence 
as a material whitewashed surface and their existence as a projected image, called forth from the storage medium of film. It is through this, the mixed cinematic space of $\mathrm{N}$ aimark's work, that he gives us not a representation of an external reality but gives us a new 'displaced' way to organise and analyse space and time. Rather than turning the objects of the world into a film, Naimark turns film into objects. D isplacements reformulates the conditions of cinema by presenting a space where projected images experimentally augment hard matter.

But Displacements, like Hansen and Rubin's installations, is not simply about producing new experiences of space through the composition of images. Instead, what is at stake in this work is the experimental demonstration of the technical conditions of images that produce new senses of time. Naimark develops a new cinematographic technique to analyse time and movement, and through this his cinematic apparatus signals a return and a reformulation of cinema's analytical roots. M uybridge, $M$ arey and $\mathrm{M}$ arinescu developed time-critical apparatuses to study movement. Naimark likewise conducts an experiment with time by producing new images of movement. However, rather than freezing time in the same way as the early experiments with photography and movement, Naimark's experiment, operating within a vastly different media culture, duplicates time. B oth the earlier chronophotography projects and Naimark's experiment demonstrate how new media can be applied to create new senses of movement and time. Marey's chronophotographic gun and M uybridge's array of cameras provides new ways to study movement in an analytical context. Similarly Naimark's experiment provides a new way to experience time as multiple in an artistic context. B oth sets of experiments are 'time-critical' in Ernst's sense as they 
are critical of time. B oth develop apparatuses to analyse the relationships of movement to different mediations of time.

\section{INSERT FIGURE 2 HERE}

FIGURE 2

M ichael Naimark, Displacements (still), 1984/2005, San Francisco M useum of M odern A rt, Photograph Scott Fisher

As has been recognised in the philosophy of science since Hacking's (1983) work on experimentation, the experimental researcher does not observe the bare facts of nature but rather 'twists the lion's tail' to "manipulate our world in order to know its secrets" (Hacking in Shadish, Cook, Campbell, 2010: 2). Through the creation of new scenarios, the experiment amounts to a "desire to uncover the new through a treatment and disruption of the real" (B rown, 2012: 71). It is in this sense that Naimark's work is experimental in that it 'uncovers the new' by exploring the temporality generated when the technical image of a stored past is put in contact with a present object. Displacement amounts to a technico-aesthetic intervention in, and manipulation of, the usual experience of objects and time to show us something new about the experience and existence of objects in time. The work disrupts the real, as Steve B rown puts it, by bringing new tools and methods of cinematic projection to bear on our experience of the world and, like Hansen and Rubin's work scaling-up the multi-temporalities generated in contemporary media culture.

\section{Technical interventions}


One of the major changes signalled by the development of the experimental devices in the scientific revolution of the $17^{\text {th }}$ century was to the relationship between reason, experience and observation. Shadish, Cook, and Campbell (2010) point out that "before the 17th century, appeals to experience were usually based on passive observation of ongoing systems rather than on observations of what happens after a system was deliberately changed. A fter the scientific revolution in the 17 th century the word experiment came to connote taking a deliberate action followed by systematic observation of what occurred afterward" (Shadish, Cook and Campbell, 2010: 2). The experiment came to stand for "a study in which an intervention is deliberately introduced in order to observe its effects" (Shadish, Cook and Campbell, 2010: 12). As Rom Harré points out, "an experiment is the manipulation of an apparatus, which is an arrangement of material stuff integrated into the material world in a number of ways" (Harré, 2003: 19). W ith the aid of apparatuses, experiments can make processes occur that have no analogue in the pre-experimental world, but that nonetheless provide new visions of the way the world looked before the experimental intervention. The experimental conditions set up by the automatic movement and organisation of images, as in Hansen and Rubin's work, Naimark's project and the examples to follow, can be understood to 'twist the lions tail', precisely in this way, by manipulating a factor in our experience of the world.

As mentioned earlier, whether ad hoc or methodical, an experiment tests causal relations by intervening and changing the existing system. Hansen and R ubin have disrupted the closed system of online social media by adding a data mining program that selects and cuts up texts, a computer program with natural language processing routines that assembles the text into patterns and an installation set-up that presents 
these texts as words, music and computer simulated voices. $N$ aimark has likewise manipulated the cinematic, literally turning projected images on themselves and experimentally studying the temporality of cinematic mediation. These types of experiments, by adding difference to a system, go about manipulating the world in order to give us an image of the world. The intervention of D isplacements experimentally demonstrates how cinema can organise time by re-imaging the past/present relationship. In their experimental application of technology, both Naimark's and Hansen and Rubin's projects, by creating new processes and technical images of the world, give us a heightened sense of the temporality generated by popular media technology. They expand on the traditional qualities of data organisation, in the case of $\mathrm{H}$ ansen and Rubin, and the cinematic, in the case of Naimark, scaling-up these media forms, to show us something about the cultural implications of signal processing and storage.

In both science and in art experimental probing intervenes in the conditions of the real. It is a process that disrupts the goings on in the world, that manipulates and cleaves open a closed system so as to generate new potentials for experience, observation and knowledge. "Experiments make a contribution when they simply probe whether an intervention-as-implemented makes a marginal improvement beyond other background variability" (Shadish, Cook and Campbell, 2001: 489). A n intervention makes a marginal improvement if it, in a world full of other variables, can be seen to indicate how things might change in relation to one another. $\mathrm{H}$ ansen and Rubin's M oveable Type and Naimark's Displacement do this by indicating how media can generate experiences of time and the relationships between past and present. To experimentally demonstrate this, in both works, new media systems were 
designed that re-purposed existing technology to heighten the media's time-critical qualities.

A similar time-critical experiment with media technology has been developed by Richard Serra in his video piece B oomerang. In B oomerang, a collaboration with the performance artist $\mathrm{N}$ ancy $\mathrm{H}$ olt, Serra experimentally applies an audio system that delays Holt's voice and records the performer-machine interaction on video. A gain, like the experiments of M uybridge, M arey and M arinescu, Serra's video piece is concerned with exploring how media can reformulate events in time. Both the experiments in chronophotography and Boomerang experimentally apply a storage medium in order to generate new ways to experience and analyse processes in time. In Boomerang Serra films Holt as she describes the experience of hearing her own voice delayed by less than a second. In the piece Holt, wearing headphones that playback microphone signal from a tape machine, tells us, in a slow, measured and seemingly artificial way, that she has the experience of "words spilling out of my head and then turning into my ear" and that "the words coming back seem slow, they don't seem to have the same forcefulness." The experimental setting of this work is designed to test the function of media in producing performances, thoughts and actions and the manner in which, as Holt puts it, levels of delay and mediation cause her to have trouble making connections between thoughts and between moments in time.

M uyebridge, $M$ arey and $M$ arinescu developed camera-based systems that processed and stored light in order to freeze and study movement. Similarly concerned with using media to create a new condition to observe and analyse behaviour, Serra applies 
a system that processes and stores sound to show us something about the behaviours triggered by television. Where the experiments with chronophotography produced an image of time as a series of movements, the delay of Serra's work produces an image of time as multi-temporal, as 'real time' is continually disrupted by moments from the past. Serra's work is different, however, from the experiments with chronophotography, as well as Naimark's and Hansen and R ubin's work, in that it amounts to an experiment on a human subject. What we see in this work, like the famous photographic records of the experiments conducted by Duchenne de B oulogne in the mid $19^{\text {th }}$ Century, is Serra applying an instrument to a subject in order study the outcome. Duchenne applied electrodes to trigger facial expressions which supposedly related directly to emotional states. Serra likewise applies electronic media to organise Holt's performance and drastically up-scales the disorientation that Serra sees in a contemporaneous television culture.

In the tradition of Nam J une Paik and W olf V ostell, Serra uses the electronic reproduction of body and voice to criticise the same electronic reproductions carried out by television. The condition for the technical image is particularly evident in this piece when a logo referencing broadcast television appears and then when a blue screen with the text A UDIO TROUBLE interrupts the performance as Serra reloads the tape machine. This immediately demonstrates how Holt's performance is dependent on and organised by the functioning and requirements of the medium. The performance cannot go on until the medium can record it. 
The experiments that I have looked at so far all involve the re-programming of machines, whether tape machines, film projection or data management software. Serra's headphones co-create Holt's performance, Naimark's recording and projection system creates the tension between past and present in his work, and Hansen and Rubin's algorithm, and the very small delays caused as signal moves through transducers, demonstrates how temporality is produced as relational rather than sequential in computer culture. Technology is used in these experiments to create an intervention in the world, to introduce difference to a system and study its effects. Philosophers of science such as Pickering (1995) and indeed Latour (1993) have repeatedly shown that humans do not live in the bare hard facts of nature but rather in the spaces cleaved open by experimental processes, and it is in these processes that, in both art and science, images and technology have intervened in, and generated, visions of the world. Peter Sloterdijk understands this particularly well, telling us that “humans have never lived in a direct relationship with 'nature,' and their cultures have certainly never set foot in the real $m$ of what we call the bare facts; their existence has always been exclusively in the breathed, divided, torn open and restored spaces." (Sloterdijk, 1998/2011: 46). Humans have never lived amongst the stable and definite objects of the world represented by positivism in science, but always in that which is experimentally produced through the invention of the laboratory, the experimental intervention of technology and the composition of world images. And it is this that the experiment of experimental art achieves: it shows us technical images of the world that up-scale the functioning of technology in the world. It does not explore the 'bare facts' of the world, but produces new spaces and new times in which to come to think about our condition of living amongst technology in the world. From the previous three sections of this paper, 'technical tests', 'technical images' and 
'technical interventions', we now have three definitions of the experimental artist, each of which is a function of the others: A $n$ experimental artist is a figure that 1 ) tests aesthetic and cultural problems by 2) providing the conditions for the emergence of technical images that 3) intervene in and disrupt the sequence of events in the real world in order to gain a new perspective on these events.

\section{Experiments in the digital humanities}

The experimental techniques applied in artworks like those by Hansen and Rubin, Serra and $\mathrm{N}$ ai mark have recently re-emerged in a different disciplinary setting that likewise uses the technical image to create new experiences of time. The digital humanities were once primarily about digitising documents and artefacts. But, contemporary digital humanities scholarship is now primarily focussed on introducing a layer of computational organisation to the study of human culture. This new organisational system is applied to cultural data to indicate qualities and relationships that would otherwise have gone unnoticed, either because realising them using conventional methods is too difficult or too time consuming. Digital humanities scholars, like the video and media artists discussed above, experimentally apply computer technology. Like Serra's delay, Naimark's experimental projection and Hansen and Rubin's natural language processing software, researchers in the digital humanities introduce difference into the world in the form of a technological reordering of events and study the outcomes. A n example of this is work conducted as part of the Stanford U niversity Spatial History Project, which uses data visualisation techniques and Global Information Systems (GIS) to resituate historical data into geographic space. One part of this research programme is a project titled Mapping the 
Republic of L etters, where data visualisation software is used to spatially map the circulation of 55,000 letters between 6,400 correspondents in what was known as the Enlightenment's R epublic of Letters, a network of intellectuals that communicated across E urope via written letters (Chang et. al. 2009).

The historical time of events is presented in this project as a geographic space where multiple times are accessed based on a set of their relations in space. U sers of the system are able to compose a history of events onto geographic space and uncover relationships by experimenting within the program. The rendering of maps made possible by the application of GIS in this humanities project also imposes a particular spatial and multi-temporal rendering of time, which can generate new patterns in the data. M apping the Republic of Letters reveals new information about communication between scholars, such as revealing the patterns of V oltaire's correspondence, which number over 15,000 letters and reveal his travel patterns around Europe, his links with other European and B ritish intellectuals, al ong with uncovering several second degree connections with B enjamin Franklin (Coleman, 2012). The project provides a spatial visualisation of these connections that allows researchers to immediately see patterns in the data as the computer organises them on a map of geographic space. W hat these experiments with time also allow us to see, as part of a larger move toward spatial history, is the patterns and insights emergent when multiple events from the past overlay one another in a multi-temporal present. Like Hansen and Rubin's, Serra's and Naimark's work, the digital humanities experiments with what, after Flusser, we might now term technical images of time. These are images that are inextricable to the technology that produced them and that generate new experiences of time through both aesthetic and technical means. The technical image produced in media art and 
the digital humanities explored here all generate multi-temporal images that provides viewers with new ways to experience the relationships between events in time, whether this be letters sent throughout $\mathrm{V}$ oltaire's life, the much tighter time differences brought together by Serra, who mingles the input signal from a microphone and the output from a tape machine, the recorded footage and actual objects brought together by N aimark or the 'real-time' and archived text feeds brought together by Hansen and Rubin's work.

A nother example of the larger trajectory in the digital humanities concerning the visualisation of 'big data' is a recent experimental project conducted by Lev M anovich and the interdisciplinary team at UC San Diego's Software Studies Initiative. Running what M anovich terms 'cultural analytics', software designers develop a programme to generate and visual ise patterns in large data sets (see M anovich and Douglass, 2011 and M anovich, 2012). They start with the question: "how can we explore patterns and relations between sets of photographs, designs or video that may number in the hundreds of thousands, millions or billions?" (M anovich, 2012: 250). M anovich's answer is to experimentally apply computational tools to organise images and re-imagine the changing world as a complex spatial visualisation. Events that once occurred in time are now organised in space. In the project $O$ ne Million M anga Pages 1, 074, 790 pages from M anga comics were uploaded and aesthetic patterns between the pages visualised based on the numerical qualities that the computer assigns to image properties (M anovich, 2012: 251). In this project the computer produced relationships that would otherwise go unnoticed by suggesting the space of variation between pages and showing how the manga 'style' moves through these variations. Rather than a standard search-retrieve system, the 
software allows a researcher to see the topological space of data, which can connect to and change shapes depending on relational criteria entered into the computer.

The move from search to visualisation in the digital humanities, here illustrated in M anovich's recent projects and Stanford's Spatial History Projects, signals a new way for a researcher to approach data. Previously the researcher was required to come to the often opaque space of the archive with a preconceived idea of what it is they were looking for: "search assumes that you want to find a needle in a haystack of information. It does not allow you to see the shape of the haystack" (M anovich, 2013). This is the reason why I have described the experiment in digital art and humanities projects as an aesthetic and technical exploration of ideas. The material processes, fidelity and indeed the programming of the technology - if it is to be invested in the development of research and the conditioning of research questions is fundamental to the emergent properties of data and the findings of the research, providing the structure necessary to visualise complex relationships between a world of images.

\section{Conclusion}

This paper has begun to unfold a possible definition of the experimental researcher in the arts and humanities, with three interlinked components: They 1) test aesthetic and

cultural problems by 2) providing the conditions for the emergence of technical images that 3) intervene in and disrupt the events of the real world in order to gain a new perspective on these events. To experiment, following the description of the 
scientific method developed in the $17^{\text {th }}$ century - whether one sticks to its reformulation set out in the falsification approach developed by Popper (1935/2002), K uhn's (1962/2012) conception of the theory ladenness of scientists, or the more 'anarchistic' approach set out by Feyerabend (1975/1993) - a researcher develops a theory via observations and then tests these observations through a set of interventions in the real. For $\mathrm{H}$ ansen and Rubin these experimental interventions involve designing an aesthetic system of audio-visual images and a technological system based on a computer program that searches a dataset for relational phrases. For the researchers at Stanford this involves working with computer scientists to develop data organisation techniques using GIS to cluster a dataset of communication in the $17^{\text {th }}$ and $18^{\text {th }}$ century, based on spatial meta-data, such as where the content originated, the sender and recipient of letters. For all of the artists and researchers discussed in this paper their experimental practice involves applying a technicoaesthetic system that re-organises signal picked up from what Flusser describes as the 'swarm of particles and quanta' that now constitute the world (Flusser, 1985/2011: 10). B ased on the programming of an apparatus, the experiment, the intervention in the real, organises the particles of the universe and in doing so generates technical images of time. As discussed throughout the paper, this technical organisation of signal is based on something that is already going on in contemporary media culture. The experimental artists and humanists discussed use cinematic equipment, data organisation software, audio equipment and GIS to scale-up the type of time al ready being produced in everyday computer culture but that quite often, without these experimental interventions, goes unnoticed. They provide the condition for the emergence of technical images, as ways of understanding the world through the automatic organisation of signal. 


\section{Acknowledgements}

M any thanks to Claudia G ehrig for all her help while I was at the ZK M archive. M any thanks also to my friend and colleague $K$ aren L ury for her feedback on an early draft of this essay.

\section{Funding}

This work was supported by a grant from the Carnegie Trust for the Universities of Scotland.

\section{R eferences}

Baird D (2003) Thing-K nowledge: Outline of a material ist theory of knowledge In:

Radder $\mathrm{H}$ (ed) The P hilosophy of Scientific Experimentation. Pittsburgh: University of Pittsburgh Press, pp. 39-67.

B rown S (2012) Experiment: A bstract experimentalism. In: Lury C and W akefield N (eds) Inventive M ethods: The Happening of the Social. London and N ew Y ork: Routledge, pp. 61-75.

Bullivant L (2005) The Listening Post. Architectural D esign 75(1): 91-93. 
Candy L (2006) Practice based research: A guide. Report from Creativity and Cognition Studios, University of Technology, Sydney.

Chang D, GeY and Song S (2009) V isualizing the republic of letters: A $n$ interactive visualization tool for exploring spatial history and the Enlightenment. A vailable at http://www.shiweisong.com/files/rpl.pdf (accessed 05 J une 2013).

Coleman N (2012) M apping the Republic of Letters. In: Open K nowledge Foundation Blog. A vailable at http://blog.okfn.org/2012/03/22/mapping-the-republic-of-letters/ (accessed 11 J une 2013).

Deleuze G (1985/2005) Cinema 2: The Time Image (trans. Hugh Tomlinson and Robert Gal eta). London and N ew Y ork: Continuum.

Eleey P (2003) M ark Hansen and B en Rubin. F rieze 75. A vailable at http://www.frieze.com/issue/review/mark_hansen_and_ben_rubin/ (accessed 1 M ay 2013).

Ernst W (2013) Digital M emory and the Archive (trans J ussi Parika). M inneapolis: University of M innesota Press.

Feyerabend P (1975/1993) Against M ethod. London:V erso B ooks. 
Flusser V (1985/2011) Into the U niverse of Technical Images (trans. Nancy A nn Roth). M inneapolis: University of M innesota Press.

Flusser V (1986) The photograph as post-industrial object: A $n$ essay on the ontological standing of photographs. Leonardo 19(4): 329-332

Flusser V (2011) The gesture of photographing (Trans. Nancy A nn Roth). J ournal of Visual Culture 10(3): 279-293

Gere C (2010) Research as art. In: Gere C and Gardiner H (eds) Art Practice in a Digital Culture. Surrey, UK: A shgate, pp. 1-8.

Groom A (2013) Time. Cambridge, M A: M IT Press.

Guarde-Hansen J, Hoskins A, and Reading, A (eds.). (2009) Save As... Digital Memories. Basingstoke, Hampshire: Palgrave M acmillan.

Hansen M and Rubin B (2002) Listening post: Giving voice to online communication. In: Proceedings of the 2002 International Conference on Auditory Display, K yoto, J apan, J uly 2-5, 2002. A vailable at 
ftp://204.178.31.32/who/cocteau.old/papers/pdf/icad2002.pdf (accessed 01 J uly 2013).

Hacking I (1983) Representing and Intervening: Introductory Topics in the Philosophy of Natural Science. Cambridge: Cambridge University Press.

Harré R (2003) The materiality of instruments in a metaphysics for experiments. In: Radder H (ed) The Philosophy of Scientific Experimentation. Pittsburgh: University of Pittsburgh Press, pp. 19-38

J ongen M (2011) On anthropospheres and aphrogrammes: Peter Sloterdijk's thought images of the monstrous. Humana.M ente J ournal of P hilosophical Studies18: 199219.

Kuhn T (1962/2012). The Structure of Scientific Revolutions. Chicago: University of Chicago Press.

Latour B (1993) We Have Never Been M odern. Cambridge, M A : Harvard University Press.

Lee P (2006) Chronophobia: On Time in the Art of the 1960s. Cambridge, M A : M IT Press. 
M anovich L (2012) How to compare one million images? In: B erry D (ed)

U nderstanding Digital Humanities. B asingstoke, UK : Palgrave, pp. 249-278.

M anovich L (2013) M edia visualization: V isual techniques for exploring large media collections. In Gates K (ed) The International Encyclopedia of M edia Studies Vol VI: M edia Studies F utures. Hoboken, NJ : W iley B lackwell, 2013. A vailable online at http://lab.softwarestudies.com/p/publications.html (accessed 04 J une 2013).

M anovich L and Douglass J (2011) V isualizing change. In: Grau O (ed) Visualizing the 21st Century. Cambridge, M A : M IT Press, pp. 315-338.

M iyazaki S (2012) A Igorhythmics: U nderstanding micro-temporality in computational cultures. Computational Culture: A J ournal of Software Studies 2: available at: http://computational culture.net/article/al gorhythmics-understandingmicro-temporality-in-computational-cultures (accessed $16 \mathrm{M}$ ay 2013).

Naimark M (2003) Sensory anomolies. In: Laurel B (ed) Design Research: M ethods and Perspectives. Cambridge, M A : M IT Press, pp. 109-117.

Naimark M (2005) Two unusual projection spaces. Presence 14(5): 597-605.

Nelson R (2013) Practice as Research in the Arts. Basingstoke, UK: Pal grave. 
Pickering A (1995) The M angle of Practice: Time, Agency and Science. Chicago: University of Chicago Press.

Popper K (1935/2002) The Logic of Scientific Discovery. London: Routledge.

Schusters J and Watchirs G (1990) Natural philosophy, experiment and discourse: B eyond the K uhn/B achelard problematic. In Le Grand H E (ed) Experimental Inquiries: Historical, Philosophical and Social Studies of Experimentation in Science. Dordrecht, The N etherlands: K luwer A cademic Publishers.

Scrivener S (2002) The art object does not embody a form of knowledge. Working Papers in Art and Design. A vailable at http://www.herts.ac.uk/artdes1/research/papers/wpades/vol2/scrivenerfull.html (accessed 07 J une 2013).

Scrivener S (2004) The practical implications of applying a theory of practice based research: a case study. Working Papers in Art and D esign 3. A vailable from http://sitem.herts.ac.uk/artdes_research/papers/wpades/vol3/ssfull.html (accessed 7 June 2013).

Shadish W, Cook T and Campbell D (2001) Experimental and Quasi-Experimental Design for Generalized Causal Inference ( $2^{\text {nd }}$ Edition). Boston: Houghton M ifflin. 
Sloterdijk P (2011) Sphere Vol 1: Bubbles: Microspherology (trans. W ieland Hoban). Los A ngeles: Smiotext(e).

V an Dijk J (2007) M ediated M emories in the Digital Age. Stanford: Stanford University Press. 